\title{
A Review of Surgical Management Affecting Forearm Rotation after Both Bone Forearm Fracture in the Pediatric Athlete: Plate versus Nail
}

\author{
Phong Truong $^{1 *}$, Eric Bradley ${ }^{1}$, Jorge Benito $^{1}$, Jonathan Schneider ${ }^{1}$, Stephen Forro ${ }^{1}$, Cindy Ho, Felix Stanziola $^{1}$ \\ ${ }^{1}$ Department of Orthopedic Surgery, Larkin Community Hospital, South Miami, FL, USA
}

Received Date: September 03, 2020; Accepted Date: September 11, 2020; Published Date: September 19, 2020

*Corresponding Author: Phong Truong, Department of Orthopedic Surgery, Larkin Community Hospital, 7000 SW 62nd Ave, Suite 401, South Miami, FL 33143, USA. Tel: +1305-284-7500; Email: Ptruong@ larkinhospital.com

\section{Abstract}

The purpose of this article is to review the outcomes of surgical fixation of pediatric both bone forearm fractures with intramedullary nailing versus plating in regards to forearm rotation and its effect on athletic performance. The majority of pediatric both bone forearm fractures can be treated nonoperatively with closed reduction and immobilization; however certain displacement parameters will benefit from operative fixation. Controversy exists on whether to fix both bone forearm fractures with intramedullary nailing or with plates and screws. Historically, it has been shown that the decrease in forearm rotation with intramedullary nailing does not affect function when performing activities of daily living, but this does not account for the rotation needed by pediatric athletes to perform specific actions such as shooting a basketball or pitching a baseball. While the more anatomic reduction with plating has led to greater ranges of forearm rotation, there has yet to be a consensus on the preferred treatment in the high demand pediatric athlete. We recommend further research examining the effects of decreased pronosupination on sport-related function in athletes that had undergone surgical intervention for both bone forearm fractures in childhood or adolescence.

Keywords: Athlete; Both Bone Forearm Fracture; Intramedullary Nail; ORIF; Orthopedic Surgery; Pediatric; Plate; Pronation; Pronosupination; Rotation; Sports; Supination

\section{Abbreviations}

BBFA : Both bone forearm

ADL : Activities of daily living

\section{Introduction}

Fractures of the forearm are some of the most common fractures encountered in the pediatric and adolescent population [1]. Some studies suggest $18 \%$ of all children will sustain a fracture of some kind by the age of 9 , with the highest incidence occurring between ages 5-14 [2]. Of pediatric forearm fractures, $75-84 \%$ occur in the distal third, $15-18 \%$ occur in the middle third, and $1-7 \%$ occur in the proximal third [3]. Additionally, many pediatric forearm fractures occur in competitive athletes. While many of these patients simply compete in their respective sporting event for enjoyment and fun, a portion of these very competitive and successful athletes compete with the goal of achieving national recognition, a collegiate scholarship, or even a professional career that could potentially springboard them to financial wealth.

Thus, with a portion of pediatric athletes suffering from both bone forearm fractures, should we treat them differently? Should we lower our threshold for rotational requirements necessary for their respective sport or consider only fixation constructs with decreased risk of loss of rotation?

With such a large number of patients sustaining these fractures, many of whom are approaching skeletal maturity, this becomes an important and evolving topic in regards to treatment options. Historically, the vast majority of these injuries have been successfully treated with closed reduction [1]. However, as fixation techniques continue to improve, there is developing interest in which patterns should warrant a specific form of fixation. Current literature identifies the two major fixation techniques as intramedullary nailing or plating. Within the cohort of patients that qualify for surgical intervention versus closed reduction, there exists further controversy 
between which is the preferred method depending on age, function, and biomechanical outcome. The goal of this article is to review the best intervention as it relates to outcomes for the competitive pediatric athlete, as there has not been a general consensus on treatment.

\section{Methods}

A review of literature was conducted. Using the MEDLINE database and Google Scholar search engine, publications in the English language were queried in regards to range of motion of the forearm, deformities affecting forearm rotation, surgical indications for BBFA fractures in pediatrics, and outcomes of surgical intervention of nailing and plating. Example search queries included "both bone forearm fracture pediatrics nail" and "functional forearm range of motion". Bibliographies of chosen studies were searched for additional sources. A total of 31 sources were included in the review.

\section{Functional Range of Motion}

Activities of daily living (ADLs) are the daily basic tasks required for an individual to thrive. These tasks include feeding, dressing, hygiene, and so forth. The majority of these tasks can be achieved with an arc of forearm flexion and extension of 100 degrees. The classic arc of motion is 30 to 130 degrees of flexion. For pronosupination, typically 100 degrees of motion divided into 50 degrees of supination and 50 degrees of pronation is necessary[4]. Mehta et al states that the normal functional range of motion is approximately 85 degrees of pronation and 75 degrees of supination, but agrees that for basic activities of daily living, 50 degrees of pronation and supination are considered adequate. When observing ADLs, maximum pronation is found typing on a keyboard, at 65 degrees [5]. Maximum supination is found when opening a door, with 77 degrees [5].This is greater than the suggested 50 degrees, however a 20 degree loss of pronosupination is considered acceptable, as motion at the shoulder can compensate for the discrepancy[6].

\section{Deformities Affecting Forearm Rotation}

Injuries resulting in angular, rotational, or translational deformities can potentially lead to alterations in the normal arc of motion. Although not clinically relevant in the average person, we speculate that even subtle derangements can affect mechanics, especially in the older pediatric population where remodeling potential lags. This may have further implications in the athletic population; however, few mechanical studies on pronosupination during sport-related motions exist.

A cadaveric study performed by Matthews et. al. reports the least amount of angulation necessary for anatomic forearm rotation. The study simulates forearm fractures with subsequent repair, and is able to demonstrate 20 degrees of angulation as the cutoff for functionally significant loss of rotation. A residual of 10 degrees or less of angulation at the mid-forearm shows no major effect on anatomic forearm rotation [7]. However, in a subsequent study, a 10 degree deformity results in a significant loss of pronosupination. In midshaft fractures versus distal fractures, pronation is affected similarly, while supination is more severely affected with middle third fractures compared to distal fractures. In the same study, pronation and supination is directly correlated with the rotational deformity [8]. Sarmiento et al reports up to 24 degree loss of pronosupination with 10 degrees of angulation [9]. When increased to 20 degrees of angulation, greater than 30 degrees of pronosupination may be lost [10].

As with angular deformities, rotation deformities may result in decreased pronation and supination. Dumont, et al finds malunions of the radius in supination of greater than 60 degrees drastically limited forearm rotation. Malrotation of both the radius and ulna in opposite directions produces the largest limitation to forearm rotation [11].

Lastly, translation and shortening has also been found to affect forearm rotation. In another cadaveric study, McHenry et al simulates forearm fracture translational displacement and finds that rotational range of motion could be decreased between 10 and 41 degrees depending on the location of the fracture and the amount of displacement [12]. Maccagnano reports deficits in pronosupination with radial shortening of greater than $5 \mathrm{~mm}[\mathbf{1 3}]$.

\section{Surgical Indications}

The initial treatment of choice for closed both bone forearm fractures in the pediatric patient remains closed reduction and immobilization [14-16]. Recently, nonsurgical approaches to treatment in some cases have been challenged in favor of operative interventions, but there is uncertainty as to whether they result in significantly enhanced outcomes [17]. Still, recent evidence suggests that certain open fractures in the pediatric patient population can be treated with conservative means [17].

Surgical intervention is indicated when there is failure to achieve acceptable reduction [14]. Noonan et al historically recommended nonoperative management for both bone forearm fractures at any level in children under the age of 9 years with less than 15 degrees of angulation and 45 degrees of rotation. In patients over 9 years of age, the tolerance for rotation decreases to 30 degrees, while the tolerance for angulation remains 15 degrees in distal fractures and 10 degrees in more proximal fractures [18]. In a more recent publication, Price et al recommends conservative management of mid-shaft and distalshaft fractures up to 15 degrees of angulation. In children over eight years old, or those with proximal shaft fractures, the acceptable angulation for nonoperative management decreases to 10 degrees. Remodeling is unreliable outside of these tolerances [19].

In order to assess rotational deformity of the forearm, Weinberg et al suggests osseous landmarks should be used. In uninjured forearms, the radial styloid is in, on average, 158 degrees of supination relative to the bicipital tuberosity. The ulnar styloid is in, on average, 185 degrees of supination relative to 
the coronoid process [20]. Identifying these on radiographs can aid in assessing rotational alignment.

\section{Outcomes of Surgical Intervention}

As the incidence of forearm fractures increases, so too will the need for operative fixation. This is especially true with severely displaced fractures that do not meet acceptable nonoperative parameters, or in those that lose reduction after immobilization. Again, there has been no general consensus on the best form of fixation.

In one study, plate fixation achieved anatomical reduction with preservation of radial bow and angulation. Nailing on the other hand, led to changes in the maximum radial bow and angulation when both ulna and radial shafts were treated. This effect was not seen in single bone fixation. Despite the subtle change in bow or angulation, these changes were within the parameters [10].

Three different studies mention that radial bow is altered with intramedullary nailing compared to plating; however, no functional deficiencies are reported on follow up for these patients [21-23]. Shah et al in a 2010 study found similar results [24]. Radial bow is translated distally in their nailing group, but this does not affect rotation. These studies indicate that anatomic radial bow is not indicative of achieving pre-fracture functional levels [25].

Multiple studies report a decrease in forearm rotation with surgical treatment. One paper mentioned $20 \%$ of operative fractures had a loss of at least 10 degrees with nailing [26]. In another study on intramedullary nailing, $18 \%$ of patients had a loss of rotation of up to 20 degrees [27]. Similar findings have been reported in other studies $[\mathbf{2 8}, \mathbf{2 9}]$.

Negative outcomes have not been completely avoided with intramedullary nailing. A meta-analysis from 2014 demonstrates a higher complication rate with nailing versus plating (13.9\% in nailing versus $3.6 \%$ in plating) [30]. Another benefit to consider is the inherent stability afforded with plating. Construct strength and return to early range of motion are two major benefits that have been reported and should be considered for the population who require a shorter return to play period [14]. Furthermore, there have been retrospective studies that have shown the opposite of the aforementioned studies. Flynn et al finds a high complication rate with intramedullary nailing defined by loss of rotation of 30 degrees or more. Other complications include a higher incidence of compartment syndrome and delayed union in the older pediatric patient [31].

\section{Conclusion}

Based on our review of the literature, it is challenging to definitively state whether plating or nailing is superior for treating BBFA fractures in the pediatric athlete. The literature suggests that plate fixation provides more anatomic alignment and improved forearm rotation when compared to intramedullary nailing. Although the decreased forearm rotation with intramedullary nailing does not affect function when performing ADLs, it is unknown whether it compromises the ability of the patient to perform sport-specific actions such as shooting a basketball or pitching a baseball. We recommend further research examining the effects of decreased pronosupination on sportsrelated function in athletes that had undergone surgical intervention for both bone forearm fractures in childhood or adolescence.

\section{Author Contribution Statement}

Authors Phong Truong, Eric Bradley, Jorge Benito, Jonathan Schneider, Stephen Forro, Cindy Ho, and Felix Stanziola contributed to the conception, design, and drafting of the work; approved the final version to be published; and agreed to be accountable for all aspects of the work.

\section{Conflicts of Interest}

We declare that we have no conflicts of interest in the authorship or publication of this paper.

\section{References}

1. Truntzer J, Vopat ML, Kane PM, Christino MA, Katarincic J, et al. (2015) Forearm diaphyseal fractures in the adolescent population: treatment and management. Eur $\mathrm{J}$ Orthop Surg Traumatol 25: 201-209. doi:10.1007/s00590014-1489-x.

2. Sinikumpu JJ, Pokka T, Serlo W (2013) The changing pattern of pediatric both-bone forearm shaft fractures among 86,000 children from 1997 to 2009. Eur J Pediatr Surg 23 :289-296. doi:10.1055/s-0032-1333116.

3. Armstrong PF, Joughin VE CH (1998) Pediatric fractures of the forearm wrist and hand. Skelet Trauma Child 3: 161258.

4. Morrey BF, Askew LJ, An KN, Chao EY (1981) A biomechanical study of normal functional elbow motion. J Bone Jt Surg - Ser A 63: 872-877.

5. Sardelli M, Tashjian RZ, MacWilliams BA (2011) Functional Elbow Range of Motion for Contemporary Tasks. J Bone Jt Surg 93: 471-477. doi:10.2106/JBJS.I.01633.

6. Mehta N, MacFarlane RJ, Brown D (2014) Traumatic disorders of forearm rotation: Anatomy, biomechanics and treatment. Br J Hosp Med 75: 72-77. doi:10.12968/hmed.2014.

7. Matthews LS, Kaufer H, Garver DF, Sonstegard DA (1982) The effect on supination-pronation of angular malalignment of fractures of both bones of the forearm. An experimental study. J Bone Jt Surg - Ser A 64: 14-17.

8. Matthews LS, Kaufer H, Garver DF, Sonstegar (1982) The effect on supination-pronation of angular malalignment of fractures of both bones of the forearm. The Journal of Bone 
\& Joint Surgery 64: 14-17. doi:10.2106/00004623198264010-00003.

9. Tarr RR, Garfinkel AI, Sarmiento A (1984) The effects of angular and rotational deformities of both bones of the forearm. An in vitro study. J Bone Jt Surg - Ser A 66: 6570. doi:10.2106/00004623-198466010-00010.

10. Sarmiento A, Ebramzadeh E, Brys D, Tarr R (1992) Angular deformities and forearm function. J Orthop Res. 1992;10(1):121-133. doi:10.1002/jor.1100100115.

11. Schemitsch EH, Jones D, Henley MB, Tencer AF (1995) A comparison of malreduction after plate and intramedullary nail fixation of forearm fractures. J Orthop Trauma 9: 8-16. doi:10.1097/00005131-199502000-00002.

12. Dumont CE, Thalmann R, Macy JC (2002) The effect of rotational malunion of the radius and the ulna on supination and pronation. An experimental investigation. $\mathrm{J}$ Bone $\mathrm{Jt}$ Surg - Ser B 84: 1070-1074. doi:10.1302/0301620X.84B7.12593.

13. McHenry TP, Pierce WA, Lais RL, Schacherer TG (2002) Effect of displacement of ulna-shaft fractures on forearm rotation: a cadaveric model. Am J Orthop (Belle Mead NJ) 31: 420-424.

14. Maccagnano G, Notarnicola A, Pesce V, Tafuri S, Mudoni S, et al. (2018) Failure Predictor Factors of Conservative Treatment in Pediatric Forearm Fractures. Biomed Res Int 2018: Article ID 5930106, 8 pages, 2018. https://doi.org/10.1155/2018/5930106

15. Vopat ML, Kane PM, Christino MA, Truntzer J, McClure P, et al. (2014) Treatment of Diaphyseal Forearm Fractures in Children. Orthop Rev (Pavia) 6: 5325 doi:10.4081/or.2014.5325.

16. Lundy DW, Busch MT (1999) Intramedullary fixation of unstable forearm fractures in children. J South Orthop Assoc 8: 269-274.

17. Dittmer AJ, Molina D, Jacobs CA, Walker J, Muchow RD (2019) Pediatric Forearm Fractures Are Effectively Immobilized with a Sugar-Tong Splint Following Closed Reduction. J Pediatr Orthop 39: E245-E247. doi:10.1097/BPO.0000000000001291.

18. Pace JL (2016) Pediatric and Adolescent Forearm Fractures: Current Controversies and Treatment Recommendations. J Am Acad Orthop Surg 24: 780-788. doi:10.5435/JAAOS-D-15-00151.

19. Noonan KJ, Price CT (1998) Forearm and distal radius fractures in children. J Am Acad Orthop Surg 6: 146-156. doi:10.5435/00124635-199805000-00002.

20. Price CT (2010) Acceptable Alignment of Forearm Fractures in Children: Open Reduction Indications. J Pediatr Orthop 30: S82-S84. doi:10.1097/BPO.0b013e3181bbf1b4.

21. Weinberg DS, Park PJ, Boden KA, Malone KJ, Cooperman DR, et al. (2016) Anatomic investigation of commonly used landmarks for evaluating rotation during forearm fracture reduction. J Bone Jt Surg - Am Vol. 98: 11031112. doi:10.2106/JBJS.15.00845.
22. Reinhardt KR, Feldman DS, Green DW, Sala DA, Widmann RF, et al. (2008) Comparison of Intramedullary Nailing to Plating for Both-Bone Forearm Fractures in Older Children. J Pediatr Orthop 28: 403-409. doi:10.1097/BPO.0b013e31816d71f2.

23. Teoh KH, Chee YH, Shortt N, Wilkinson G, Porter DE. An age- and sex-matched comparative study on both-bone diaphyseal paediatric forearm fracture. J Child Orthop. 2009;3(5):367-373. doi:10.1007/s11832-009-0197-2. https://pubmed.ncbi.nlm.nih.gov/19701786/

24. Patel A, Li L, Anand A (2014) Systematic review: Functional outcomes and complications of intramedullary nailing versus plate fixation for both-bone diaphyseal forearm fractures in children. Injury 45: 1135-1143. doi:10.1016/j.injury.2014.04.020.

25. Shah AS, Lesniak BP, Wolter TD, Caird MS, Farley FA, et al. (2010) Stabilization of adolescent both-bone forearm fractures: A comparison of intramedullary nailing versus open reduction and internal fixation. J Orthop Trauma 24: 440-447. doi:10.1097/BOT.0b013e3181ca343b.

26. Kang SN, Mangwani J, Ramachandran M, Paterson JMH, Barry M (2011) Elastic intramedullary nailing of paediatric fractures of the forearm: A decade of experience in a teaching hospital in the United Kingdom. J Bone Jt Surg Ser B 93: 262-265. doi:10.1302/0301-620X.93B2.24882.

27. Martus JE, Preston RK, Schoenecker JG, Lovejoy SA, Green NE, et al. (2013) Complications and outcomes of diaphyseal forearm fracture intramedullary nailing: A comparison of pediatric and adolescent age groups. J Pediatr Orthop 33: 598607. doi:10.1097/BPO.0b013e3182a11d3b.

28. Kapoor V, Theruvil B, Edwards SE, Taylor GR, Clarke NMP, et al. (2005) Flexible intramedullary nailing of displaced diaphyseal forearm fractures in children. Injury 36: 1221-1225. doi:10.1016/j.injury.2005.06.033.

29. Kapila R, Sharma R, Chugh A, Goyal M (2016) Evaluation of Clinical Outcomes of Management of Paediatric Bone Forearm Fractures using Titanium Elastic Nailing System: A Prospective Study of 50 Cases. J Clin Diagn Res 10: RC12-RC15. doi:10.7860/JCDR/2016/22040.8917.

30. Garg NK, Ballal MS, Malek IA, Webster RA, Bruce CE (2008) Use of elastic stable intramedullary nailing for treating unstable forearm fractures in children. J Trauma - Inj Infect Crit Care 65: 109-115. doi:10.1097/TA.0b013e3181623309.

31. Baldwin $\mathrm{K}$, Morrison MJ, Tomlinson LA, Ramirez R, Flynn JM (2014) Both bone forearm fractures in children and adolescents, which fixation strategy is superior - Plates or nails? A systematic review and meta-analysis of observational studies. J Orthop Trauma 28: e8e14.doi:10.1097/BOT.0b013e31829203ea.

32. Flynn JM, Jones KJ, Garner MR, Goebel J. Eleven years experience in the operative management of pediatric forearm fractures. J Pediatr Orthop 30: 313-319. doi:10.1097/BPO.0b013e3181d98f2c. 